\title{
A Long-Duration (118-day) Backpacking Trip (2669 km) Normalizes Lipids Without Medication: A Case Study
}

\author{
Dale DeVoe, PhD; Richard Gay Israel, EdD; Tiffany Lipsey; Wyatt Voyles, MD \\ From the Colorado State University and Heart Center of the Rockies, Fort Collins, CO (Drs DeVoe, Israel and Voyles and Ms Lipsey).
}

\begin{abstract}
Objective.-To evaluate the effects of a long-distance backpacking trip on body composition, weight, blood lipids, and lipoproteins.

Methods.-Single-subject (male, aged 49 years) study of an experienced backpacker who hiked 118 days on the Appalachian Trail. Outcome measures that were assessed pre-hike and post-hike included body fat $(\%)$ by hydrostatic weighing and skinfold assessment, height and weight, body mass index (BMI), circumference measurements (umbilicus, anterior suprailiac, maximum hip, greater trochanter, minimum waist, umbilicus/anterior suprailiac ratio), and blood pressure (systolic and diastolic at rest and peak). Dietary analyses (total kilocalories, protein, carbohydrate, fat, cholesterol, saturated fat, monounsaturated fat, polyunsaturated fat, dietary fiber) were conducted pre-hike, on days 54 through 56, and on days 98 through 100. Blood lipids and lipoproteins (triglycerides, high-density lipoprotein, low-density lipoprotein) were measured pre-hike, on day 89 , and post-hike.

Results.-Pre-post differences showed decreases in body weight, from $85.3 \mathrm{~kg}$ to $73.9 \mathrm{~kg}(-11.4$ [-13.4\%]); percent body fat, hydrostatic weighing, from 25.18 to $14.31(-10.87$ [ $-43.2 \%])$; percent body fat, skinfolds (7-site), from 23.79 to 11.61 (12.18 [-51.2\%]); and BMI, from 29.37 to 25.46 $(-3.91[-13.3 \%])$. Pre-post differences in blood lipid changes over the course of 118 days were as follows: triglycerides $\left(\mathrm{mg} \cdot \mathrm{dL}^{-1}\right)$ fell from 319 to $79(-240[-75 \%])$; total cholesterol $\left(\mathrm{mg} \cdot \mathrm{dL}^{-1}\right)$ fell from 276 to $196(-80[-29 \%])$; high-density lipoprotein (HDL) $\left(\mathrm{mg} \cdot \mathrm{dL}^{-1}\right)$ rose from 46 to $63(+17$ [+37\%]); low-density lipoprotein (LDL) $\left(\mathrm{mg} \cdot \mathrm{dL}^{-1}\right)$ fell from 167 to $118(-49[-29 \%])$; LDL/HDL ratio fell from 3.63 to $1.87(-1.76[-48 \%])$; and total cholesterol/HDL ratio fell from 6.00 to 3.11 $(-2.89[-48 \%])$.

Conclusion.- The physical activity and diet associated with an extended backpacking adventure can considerably reduce and clinically normalize blood lipids and lipoproteins without medication and can very positively affect body composition and weight.
\end{abstract}

Key words: backpacking trip, physical activity, lipids, lipoproteins, cholesterol

\section{Introduction}

Numerous studies utilizing a variety of intensities and durations of physical activity have shown in general a moderate positive effect on metabolic and cardiovascular risk factors. ${ }^{1,2}$ A review article of 51 published studies found that aerobic exercise performed at moderate to

The work described in the manuscript has been formally presented at the American College of Sports Medicine (ACSM) Annual Meeting, New Orleans, LA, 2007.

Corresponding author: Dale DeVoe, PhD, Professor and Associate Dean, College of Applied Human Sciences, 214 L.L. Gibbons Building, Colorado State University, Fort Collins, CO 80523-1501 (e-mail: devoe@cahs.colostate.edu). high intensity and of at least 12 weeks in duration inconsistently results in an improvement in blood lipid profiles. ${ }^{1}$ As a result of the numerous confounding variables and methodological flaws that were noted in many of the studies surveyed in this report, the data were found to be insufficient to establish dose-response relationships. The most commonly observed change was an increase in high-density lipoprotein (HDL) (change in HDL ranged from a decrease of 5.8\% to an increase of approximately $25 \%$, with a mean increase of $4.6 \%$ across these reviewed studies), with mean reductions in low-density lipoprotein (LDL) (5.0\%), total cholesterol (TC) (1.0\%), and triglycerides $(3.7 \%)$ less frequently observed. In an additional review article ${ }^{2}$ 
of 25 walking programs of at least 8 weeks in duration, reductions in lipoproteins (LDL and TC/HDL) were found to be independent of changes in body composition. These findings indicate the usefulness of the physical activity associated with backpacking as a relatively lowcost strategy for reducing the risk for cardiovascular disease. In 2002, 73.5 million $(34.5 \%)$ people in the United States hiked and 24.5 million $(11.5 \%)$ people went backpacking at least once. ${ }^{3}$

The Appalachian Trail Conservancy (Harpers Ferry, WV) estimates that 3 to 4 million visitors hike a portion of the Appalachian Trail each year, with almost 3000 yearly reported long-distance backpackers. ${ }^{4}$ The route of the trail closely follows the ridge line of eastern America's Appalachian Mountain chain for $3500 \mathrm{~km}$, with its southern terminus in northern Georgia and northern terminus in north central Maine. Most of these reported long-distance backpackers are less than 25 or greater than 45 years of age. Despite the prevalence of backpacking, there has been modest assessment of the health needs of long-distance backpackers ${ }^{5-7}$ and no formal documentation on the impact of backpacking long distances over an extended period of time on cardiovascular disease risk factors (eg, dyslipidemia, elevated blood pressure, high abdominal adiposity). Accordingly, this field study provided the extended time necessary to assess the conditioning effects of a long-distance hike in a single individual. The significance of this study lies in the usefulness of the physical activity associated with backpacking to enhance physical health and the need to promote the use of public lands.

\section{Methods}

The participant (male, aged 49 years) was an experienced backpacker. Institutional review board approval was sought and waived for this study as the participant was an investigator. The participant completed a long-distance hike of 118 total days on the Appalachian Trail, during which 104 days were spent hiking a distance of 2669 kilometers. The participant began the hike in Georgia on January 3 and finished in the White Mountains of New Hampshire on May 1. During this time the participant was backpacking under a wide assortment of environmental conditions and terrain. On higher altitudes $(1500-1800+\mathrm{m})$ in the southern Appalachians the participant encountered snow for 5 weeks, with typical temperatures in the $-6^{\circ} \mathrm{C}$ to $0^{\circ} \mathrm{C}$ range. Snow depths ranged from 5 to $7 \mathrm{~cm}$ to $40+$ centimeters, and on many mountain ridges the participant encountered drifts that were knee to thigh deep. Throughout March and April the participant encountered customary east coast spring temperatures ranging from $-6^{\circ} \mathrm{C}$ to $10^{\circ} \mathrm{C}$. High winds and rain on a number of days also were environmental factors that made for hiking in very demanding climatic conditions.

Baseline measures were conducted 12 days before the start of the hike, and post-hike assessments were conducted 2 days after completion of the hike. Percent body fat $(\%)$ by hydrostatic weighing at residual volume and skinfold assessment (7-site) using Harpenden calipers (British Indicators, St Albans Herts, UK) were measured pre- and post-hike. ${ }^{8-11}$ The 7 skinfold sites previously described by Jackson and Pollock ${ }^{9}$ were measured on the right side of the body to the nearest $0.2 \mathrm{~mm}$, with the pinch maintained while the measurement was taken. The calipers were placed $\sim 1 \mathrm{~mm}$ below the pinch of the thumb and index finger, which is halfway between the crest and base of the fold and perpendicular to the skinfold. Two measurements were assessed of each skinfold site, rotating through all 7 sites in a fixed order, and the measurements were averaged for use in the calculation. These measurements were within $2.0 \mathrm{~mm}$ of each other in terms of precision and accuracy. A single investigator performed all the measurements. The Jackson-Pollock equation was used to calculate body density $(1.112-0.00043499$ [sum of 7 skinfolds] + 0.00000055 [sum of skinfolds] ${ }^{2}-0.00028826$ [age]), which has a reported standard error of estimate of 0.008 , or $\sim 3.5 \%$ fat. $^{8-10}$ Body density was determined via hydrostatic weighing using measured residual lung volume (VMax 229, SensorMedics, Yorba Linda, CA). Body fat percentage was derived from body density using the Siri equation, which is \% fat $=(495 /$ body density) $-4500^{8,10,11}$

Height and weight were measured on a standard physician's scale and stadiometer (Healthometer, Ridgeview, IL). Height was measured to the nearest $0.5 \mathrm{~cm}$ and weight was measured to the nearest $0.1 \mathrm{~kg}$. Body mass index (BMI) was then calculated as the weight divided by the square of the height $\left(\mathrm{kg} \cdot \mathrm{m}^{-2}\right){ }^{10}$ Circumferences were measured using a Gulick tape, with the tape parallel to the floor, at the following sites: (waist: at the level of the umbilicus; anterior suprailiac: at the level at which the anterior iliac crest begins to decline downwards; maximum hip: at the level of the maximal hip circumference; greater trochanter: at the level of the greater trochanter of the femur; minimum waist: narrowest part of torso between the umbilicus and xiphoid process). These measurements were taken preand post-hike. Vital signs and electrocardiogram with Mason-Likar configuration ${ }^{12}$ were taken at rest, while supine, sitting and standing, and during graded exercise testing.

The participant performed maximal oxygen consumption tests pre- and post-hike, walking using a modified 
Balke protocol on a Quinton Motorized treadmill (Seattle, WA) with speed at $6.1 \mathrm{~km} \cdot \mathrm{h}^{-1}$ and initial grade at $0 \%$, while supervised by a cardiologist. The first minute the grade was increased to $2 \%$, and then the treadmill grade was increased $1 \%$ every minute thereafter. An automated metabolic cart (Truemax 2400, Parvo Medics Inc, Sandy, UT) recorded the following parameters every 15 seconds: time, percent of expired air that is carbon dioxide, percent of expired air that is oxygen, pulmonary ventilation, oxygen consumption $\left(\mathrm{VO}_{2}\right)$, carbon dioxide production, and respiratory exchange ratio, which is the ratio of carbon dioxide production to oxygen consumption. Heart rate was constantly monitored and recorded using a standard 12-lead electrocardiogram. ${ }^{12}$ A maximal stress test was achieved when the participant reached voluntary exhaustion, heart rate was at or above the age-predicted heart rate maximum (220 age [years]), and respiratory exchange ratio was greater than 1.1. $\mathrm{VO}_{2 \text { peak }}$ was defined as the highest oxygen consumption value achieved during the final stages of the test. $^{10}$

Standard fasting (12-hour) blood work was determined pre-hike, during the hike, and post-hike. Standard fasting blood work for pre- and post-hike were analyzed by the same off-site contract laboratory (Poudre Valley Hospital, Fort Collins, CO). Here, blood parameters were assessed from unfrozen plasma samples using a Beckman Coulter DxC 800 Synchron Clinical System (Beckman Coulter Inc, Fullerton, CA). Low-density lipoprotein was measured using the Friedewald equation. ${ }^{13}$ For the during-hike assessment, the participant had completed 89 days $(2059 \mathrm{~km})$ of the hike when the blood was drawn and analyzed (Labcorp Holdings Regional Laboratory, Raritan, NJ) for standard blood work during a day off from hiking.

Dietary analysis (average 3-day analysis) was conducted pre-hike and during the hike on 2 occasions; after the participant completed 56 days and $1365 \mathrm{~km}$ (days 54, 55, and 56) and near the end of the hike, after the participant completed 100 days and $2500 \mathrm{~km}$ (days 98, 99, and 100). The participant recorded food intake for 3 days and provided details on the amounts and descriptions of every item of food consumed. On items that were commercially prepared, the number of calories and the grams of carbohydrate, protein, and fat were determined from the manufacturer's label. The diet records were analyzed with Axxya Systems Nutritionist Pro (Stafford, TX) software to obtain nutrient intake measurements.

\section{Results}

Table 1 summarizes pre-post differences in anthropometric and blood pressure measurements. Substantial decreases were found for body weight, body fat (hydrostatic weighing and skinfolds), and BMI. Both systolic and diastolic blood pressure levels, which were elevated before the hike, lowered, with diastolic showing the largest percentage decrease. The pre-hike graded exercise test was terminated by the physician after the 12th minute due to high blood pressure readings, so that the participant's peak heart rate and peak oxygen consumption $\left(\mathrm{Vo}_{2 \text { peak }}\right)$ recorded at that time are listed as the estimated maximal values.

Table 2 shows the pre-hike, day-89, and post-hike differences in blood lipids over the course of the 118 days, with large decreases in triglycerides, total cholesterol, LDL, LDL/HDL ratio, and TC/HDL ratio, and the corresponding increase in HDL. The dietary analyses (Table 3) conducted during the hike show the participant consuming a diet with a high percentage of fat.

\section{Discussion}

Although the current study did not assess energy expenditure, it could be postulated that the participant in this study performed backpacking primarily at a low to moderate exercise intensity in order to meet the demand of engaging in backpacking for an extended period of time. Given the environmental conditions (cold, hiking through snow) and variable nature of terrain (uphill, downhill, uneven), fluctuations in energy expenditure would naturally occur and would demonstrate bouts of time during which the participant was working more at moderate and high levels of exercise intensity. The overall relatively low to moderate exercise intensity can be explained by the necessity for the participant to adapt physical exertion to the many hours of backpacking effort each day. It is possible that the participant's caloric needs were slightly increased in response to living in the cold ambient temperatures encountered during much of this expedition in order to maintain thermal body comfort. The need to maintain thermoregulation potentially contributes to an increased energy requirement in the cold, as it has been established that exposure to cold increases oxygen consumption and metabolic rate. ${ }^{14}$ As the participant became more conditioned to backpacking every day and subsequently increased the usual daily amount of time spent hiking, daily gross energy expenditure would most likely increase. The subsequent change in body mass to a higher muscle to fat ratio that occurred during the longdistance hike could also affect daily caloric demand.

The caloric intake of the participant, as assessed by dietary analyses during the backpacking expedition, was insufficient to maintain body weight. When comparing total energy intake pre-hike to that recorded during the hike, the diet composition was altered without a marked 
Table 1. Anthropometrics and vital signs of a long-distance backpacker

\begin{tabular}{|c|c|c|c|}
\hline Variable & Pre & Post & Pre-post difference (\% change) \\
\hline Height $(\mathrm{cm})$ & 170 & 170 & $0.0(0)$ \\
\hline Body weight (kg) & 85.3 & 73.9 & $-11.4(-13.4)$ \\
\hline Body fat $(\%)$, hydrostatic weighing & 25.18 & 14.31 & $-10.87(-43.2)$ \\
\hline Body fat $(\%)$, skinfolds (7-site) & 23.79 & 11.61 & $-12.18(-51.2)$ \\
\hline Body mass index (BMI) & 29.37 & 25.46 & $-3.91(-13.3)$ \\
\hline \multicolumn{4}{|l|}{ Circumference $(\mathrm{cm})$} \\
\hline $\begin{array}{l}\text { Umbilicus } \\
\text { Anterior suprailiac } \\
\text { Maximum hip (hip) } \\
\text { Greater trochanter } \\
\text { Minimum waist (waist) }\end{array}$ & $\begin{array}{r}100.9 \\
99.7 \\
104.8 \\
103.8 \\
95.9\end{array}$ & $\begin{array}{l}84.8 \\
88.3 \\
95.9 \\
95.9 \\
83.2\end{array}$ & $\begin{aligned}-16.1 & (-15.9) \\
-11.4 & (-11.4) \\
-8.9 & (-8.5) \\
-7.9 & (-7.6) \\
-12.7 & (-13.2)\end{aligned}$ \\
\hline Waist to hip ratio & 0.915 & 0.868 & $-0.047(-5.1)$ \\
\hline Heart rate rest $_{\text {(beats/min) }}$ & 60 & 58 & $-2(3.3)$ \\
\hline Heart rate $_{\text {peak }}$ (beats/min) & 168 & 188 & $+20(+11.9)$ \\
\hline $\mathrm{VO}_{2 \text { peak }}\left(\mathrm{mL} \cdot \mathrm{kg}^{-1} \cdot \min ^{-1}\right)$ & 32.8 & 44.7 & $+11.9(+36.3)$ \\
\hline Systolic blood pressure at rest $(\mathrm{mm} \mathrm{Hg})$ & 132 & 124 & $-8(-6.1)$ \\
\hline Diastolic blood pressure at rest $(\mathrm{mm} \mathrm{Hg})$ & 98 & 78 & $-20(-20.4)$ \\
\hline Peak systolic blood pressure (mm Hg) & 238 & 226 & $-12(-5)$ \\
\hline Peak diastolic blood pressure (mm Hg) & 110 & 110 & $0.0(0)$ \\
\hline Exercise duration (min) & 11 & 19 & $+8(+72.7)$ \\
\hline
\end{tabular}

change in total energy intake. This alone should have relatively modest effects on body weight and body fat content. Demonstrating typical response during resupply stops along the way, the participant consumed larger quantities of food with high fat content, which exceeded the standard consumption during the hike. Both type and amount of food were considered carefully during the replacement of provisions (along with impact on backpack weight), and the participant self-selected a diet with a high percentage of fat. The usual food sources were assorted pastries, granola/nut bars, cheese, tortillas, chocolate bars, and freeze-dried meals. For the first few days after resupply the participant would also consume meat (salami) or boiled eggs. The participant gained significant health benefits attributed to the large amount of extended physical activity in spite of consuming a diet with a high percentage of fat, as evidenced by the dietary analyses.

Despite the consumption of a high-fat (38\%-49\% of total kilocalories) diet, there were considerable improvements in blood lipids. Pre-hike measurements of TC and LDL were both classified as high and improved to desirable and near-optimal levels, respectively, according to the National Cholesterol Education Program. ${ }^{10}$ Improvements in TC yield a $20 \%$ reduction in cardiovascular disease (CVD) risk. ${ }^{15}$ As expected, HDL rose

Table 2. Blood lipid profile of a long-distance backpacker

\begin{tabular}{lcccc}
\hline \multicolumn{1}{c}{ Variable } & Pre & Day 89 & Post & Pre-post difference $(\%$ change) \\
\hline Triglycerides $\left(\mathrm{mg} \cdot \mathrm{dL}^{-1}\right)$ & 319 & 111 & 79 & $-240(-75)$ \\
Total cholesterol $\left(\mathrm{mg} \cdot \mathrm{dL}^{-1}\right)$ & 276 & 189 & 196 & $-80(-29)$ \\
High-density lipoprotein $\left(\mathrm{HDL}, \mathrm{mg} \cdot \mathrm{dL}^{-1}\right)$ & 46 & 68 & 63 & $+17(+37)$ \\
Low-density lipoprotein $\left(\mathrm{LDL}, \mathrm{mg} \cdot \mathrm{dL}^{-1}\right)$ & 167 & 99 & 118 & $-49(-29)$ \\
LDL/HDL ratio & 3.63 & 1.46 & 1.87 & $-1.76(-48)$ \\
Total cholesterol/HDL ratio & 6.00 & 2.78 & 3.11 & $-2.89(-48)$ \\
\hline
\end{tabular}


Table 3. Diet record nutrition summary (average 3-day analysis) of a long-distance backpacker

\begin{tabular}{lccc}
\hline \multicolumn{1}{c}{ Variable } & Pre & Day 56 & Day 100 \\
\hline Kilocalories (kcal)* & 2738 & 2653 & 3130 \\
$\quad$ Protein (kcal) & $492(20 \%)$ & $284(12 \%)$ & $444(14 \%)$ \\
$\quad$ Carbohydrate (kcal) & $1132(46 \%)$ & $924(39 \%)$ & $1552(48 \%)$ \\
$\quad$ Fat (kcal) & $828(34 \%)$ & $1143(49 \%)$ & $1215(38 \%)$ \\
Cholesterol (mg) & 376 & 110 & 195 \\
Saturated fat (g) & 35.7 & 31.9 & 48.7 \\
Monounsaturated fat (g) & 28.4 & 11.2 & 38.9 \\
Polyunsaturated fat (g) & 11.4 & 5.5 & 19.9 \\
Dietary fiber (g) & 16.7 & 31.7 & 25.5 \\
\hline
\end{tabular}

*Values in parentheses equal percentage of daily kilocalories that comprised, respectively, kilocalories of protein, carbohydrates, and fat.

with increased physical activity. Of note, the increase in HDL was high enough to classify it as a negative risk factor for CVD. In addition, this improvement produces an $85 \%$ decrease in CVD risk. ${ }^{16}$ The reduction in triglycerides from $319 \mathrm{mg} \cdot \mathrm{dL}^{-1}$ to $79 \mathrm{mg} \cdot \mathrm{dL}^{-1}$ reflects an $\sim 80 \%$ reduction in CVD risk. ${ }^{17}$ Changes in blood lipids have been shown to be associated with reduced body fatness rather than increased aerobic fitness ${ }^{18}$; however, walking has reduced LDL and the ratio of TC to HDL independent of changes in body composition. ${ }^{2}$ The observed changes in blood lipids and lipoproteins in this study were considerably more marked than the moderate positive effects found in previous published studies on exercise training alone or in combination with dietary intervention. ${ }^{1}$ The effects of both environmental factors and genetic factors on CVD risk factors require more well-controlled studies. With extended knowledge on these factors we may ascertain when and at what rate specific changes in body composition, weight, and blood lipids occur.

Changes in body composition measurements indicate reduction in risk for all-cause mortality. Specifically, while BMI remained in the overweight category, improvements in this parameter were substantial, reflecting a weight loss of $11.4 \mathrm{~kg}$. The pre-hike BMI of 29.37 was almost classified as grade I obesity (30.0-34.9). ${ }^{10}$ The post-hike BMI was nearly in the normal weight category at 25.46 , with less than 25.0 considered normal weight. ${ }^{10}$ Waist circumference improved from increased risk pre-hike (above 0.90) to low risk post-hike. ${ }^{10}$

In the current study, the participant's total daily physical activity is estimated to be higher compared to levels in previous published studies on exercise training at a moderate to hard intensity, 3 to 5 times per week for
30 minutes per session. It is postulated that the participant's physical exertion (backpacking many hours each day) combined with total energy intake similar to the pre-expedition amount interacted to affect body composition, weight, and blood lipids to a greater degree. The participant's fat-free mass was slightly reduced by $0.5 \mathrm{~kg}$ from baseline to post-hike. Given the higher level of daily physical activity combined with a substantial negative energy balance, it is remarkable the participant did not experience a larger reduction in fat-free mass. Subcutaneous fat loss was more pronounced on the trunk and abdominal visceral fat area than on the limbs, as estimated from skinfolds. The participant reported an increase in muscle mass of the legs, with a decrease in muscle mass of the arms, shoulders, and chest. The physical activity associated with long-distance backpacking could have resulted in a redistribution of skeletal muscle tissue. Specifically, the daily level of negative energy balance coupled with reduced activity of the arms may have resulted in a loss of lean mass along with adipose tissue in the upper body, and the increased amount of time spent walking coupled with the additional bearing of pack weight could have increased skeletal muscle mass of the legs. This observation is in contrast to previously reported findings that there is a uniform preservation of skeletal muscle, indicating that there is no increase in skeletal muscle in one anatomical region that is masked by a corresponding decrease in another. ${ }^{19}$ Future investigations could confirm that the physical activity associated with longdistance backpacking results in a redistribution of skeletal muscle tissue.

This is a single case study, and, therefore, the findings are preliminary but indicate that the physical activity associated with an extended backpacking adventure can significantly reduce and clinically normalize blood lipids and lipoproteins without medication and can very positively affect body composition and weight. In the current study, the participant's baseline lipid levels were elevated, so these results may only be relevant for individuals who are overweight and who have high blood lipid and lipoprotein levels. Further study to examine the effects of long-distance backpacking on body composition, weight, blood lipids, and lipoproteins is warranted.

\section{References}

1. Leon A, Sanchez O. Response of blood lipids to exercise training alone or combined with dietary intervention. Med Sci Sports Exerc. 2001;33:S502-S529.

2. Kelley G, Kelley K, Tran ZV. Walking, lipids, and lipoproteins: a meta-analysis of randomized controlled trials. Prev Med. 2004;38:651-661. 
3. National Survey on Recreation and the Environment (NSRE): 2000-2002. American's participation in outdoor recreation: results from NSRE (with unweighted data). Available at: http://www.srs.fs.usda.gov/trends/Nsre/Rnd1t11unweightrpt. pdf. Accessed November 14, 2007.

4. Appalachian Trail Conservancy. Available at: http://www. appalachiantrail.org/. Accessed June 12, 2008.

5. Boulware D, Forgey W, Martin W. Medical risks of wilderness hiking. Am J Med. 2003;114:288-293.

6. Crouse B, Josephs D. Health care needs of Appalachian Trail hikers. J Fam Pract. 1993;36:521-525.

7. Puretz S. Health problems of the long-distance backpacker. Aust J Sci Med Sport. 1992;24:55-59.

8. Israel RG, Houmard J, O'Brien K, McCammon M, Zamora B, Eaton A. Validity of a near-infrared spectrophotometry device for estimating human body composition. Res $Q$ Exerc Sport. 1989;60:371-383.

9. Jackson AS, Pollock ML. Practical assessment of body composition. Physician Sports Med. 1985;13:76-90.

10. American College of Sports Medicine. ACSM's Guidelines for Exercise Testing and Prescription. 7th ed. Philadelphia, PA: Lippincott Williams \& Wilkins; 2006.

11. Siri WE. The Gross Composition of the Body. Advances in Biological and Medical Physics IV. New York, NY: Academic Press; 1956.

12. Mason R, Likar L. A new system of multiple leads exercise ECG. Am Heart J. 1966;2:196-205.
13. Friedwald W, Levy R, Fredrickson D. Estimation of the concentration of low density lipoprotein cholesterol in plasma without use of the preparative ultracentrifuge. Clin Chem. 1972;18:499-502.

14. Timmons B, Araujo J, Thomas T. Fat utilization enhanced by exercise in a cold environment. Med Sci Sports Exerc. 1985; 17:673-678.

15. Anderson KM, Castelli WP, Levy D. Cholesterol and mortality. 30 years of follow-up from the Framingham Study. JAMA. 1987;257:2176-2180.

16. Gordon DJ, Probstfield JL, Garrison RJ, et al. High-density lipoprotein cholesterol and cardiovascular diseasefour prospective American studies. Circulation. 1989;79: $8-15$.

17. Hokanson JE, Austin MA. Plasma triglycerides level is a risk factor for cardiovascular disease independent of highdensity lipoprotein cholesterol level: a meta-analysis of population-based prospective studies. J Cardiovasc Risk. 1996;3:214-219.

18. Katzmarzyk P, Leon A, Rankinen $\mathrm{T}$, et al. Changes in blood lipids consequent to aerobic exercise training related to changes in body fatness and aerobic fitness. Metabolism. 2001;50:841-848.

19. Ross R, Rissanen J, Pedwell H, Clifford J, Shragge P. Influence of diet and exercise on skeletal muscle and visceral adipose tissue in men. J Appl Physiol. 1996;81: 2445-2455. 